九州大学学術情報リポジトリ

Kyushu University Institutional Repository

\title{
Antibacterial compounds from shoot skins of moso bamboo (Phyllostachys pubescens)
}

Tanaka, Akinobu

Department of Agro-environmental Sciences, Faculty of Agriculture, Kyushu University

Shimizu, Kuniyoshi

Department of Agro-environmental Sciences, Faculty of Agriculture, Kyushu University

Kondo, Ryuichiro

Department of Agro-environmental Sciences, Faculty of Agriculture, Kyushu University

http://hdl. hand le. net/2324/25734

出版情報: Journal of Wood Science, 2012-11. Springer Japan

バージョン：

権利関係: (C) The Japan Wood Research Society 2012 


\section{Title}

Antibacterial compounds from shoot skins of moso bamboo (Phyllostachys pubescens).

\section{Type of article}

Original articles

\section{Authors}

Akinobu Tanaka ${ }^{1}$, Kuniyoshi Shimizu ${ }^{1}$, Ryuichiro Kondo ${ }^{1}$

\section{Affiliation}

1. Department of Agro-environmental Sciences, Faculty of Agriculture, Kyushu University, 6-10-1 Hakozaki, Higashi-ku, Fukuoka, 812-8581, Japan

To whom correspondence should be addressed.

Kuniyoshi Shimizu

Address: 6-10-1 Hakozaki, Higashi-ku, Fukuoka, Japan, 812-8581

E-mail: shimizu@agr.kyushu-u.ac.jp

Phone/Fax: +81-92-642-3002

\section{Keywords}

Antibacterial activity; Moso bamboo shoot skin; Phyllostachys pubescens; Phytosterol 


\begin{abstract}
Bamboo is intricately associated with human activity, and its usefulness is well known. For example, its roots and leaves have been used as medicinal products. Also, studies on the medicinal properties of bamboo leaves have shown antioxidant, anticancer, and antibiotic properties. In this study, we determined that the dichloromethane soluble of the methanol extract from the bamboo shoot skin (Phyllostachys pubescens) inhibited the growth of Staphylococcus aureus. The active constituents were isolated and identified as stigmasterol and dihydrobrassicasterol by NMR and mass spectrometry. These compounds inhibited the growth of S. aureus and Escherichia coli. Also, from the standpoint of structure-activity relationships, the activities of these phytosterols depend on their side chain structures. These findings indicate that the extracts of bamboo shoot skins as well as its active compounds in the skins potentially useful as antibacterial materials.
\end{abstract}




\section{Text}

\section{Introduction}

Recently, chemical food additives such as paraben have been reported to have harmful effects [1, 2]. Despite this, such additives are still used as preservatives in foods, cosmetics, and medical products. Meanwhile, consumer demand to ensure that only safe additives are used is increasing every year. This has led to popular movements to reduce the use of synthetic chemical compounds in foods and cosmetics. Hence, the emergence of materials having less harmful effects, and preferably natural material, would be highly desirable if their safety to consumers could be guaranteed. Staphylococcus aureus is a major food pathogen. These bacteria live on human skin and infect the body through wounds or foods. They produce several toxins such as enterotoxin-A and -D [3]. These toxins cause abdominal pain, vomiting, and diarrhea. Because they grow in foods; it is important to prevent their growth in foods. Research into natural products that can prevent the growth of bacteria in foods has been underway in many laboratories.

Bamboo is well known for its usefulness. For example, its roots and leaves have been used medicinally. Studies have also revealed that bamboo leaves have antioxidant, anticancer and antibiotic properties $[4,5]$. In these studies, various active compounds were separated from the leaves, such as flavones, glycosides, phenolic acids, coumarin lactones, anthraquinones, and amino acids $[6,7,8,9$, 10]. Also, 2,6-dimethoxy-p-benzoquinone obtained from the skin of the bamboo trees was found to have antibiotic activities, as were two chitin-binding peptides: Pp-AMP1 and Pp-AMP2, that were isolated from bamboo shoots [11, 12]. Tricin and taxifolin, found in the bamboo sheath, reportedly have antioxidant activity [13].

The present study focused on moso bamboo shoot skins (Phyllostachys pubescens), which have been traditionally used for packaging food. For example, bamboo shoot skin is used as a preservative container to maintain the quality of tea leaves in China and has been used to wrap rice balls and meats in Japan. Fukuoka prefecture is the major cultivation area of bamboo shoots in Japan. A lot of food and food ingredients are produced from bamboo shoots, and bamboo shoot skin is a large by product of food processing. These skins are often composted, but they decompose slowly, so most bamboo shoot skins are burned. It is essential to utilize bamboo shoot skins efficiently.

Previously, we reported that the shoot skin of a bamboo species ( $P$. pubescens) and its dichloromethane extract show antibacterial activity against S. aureus [14]. However, 
the active compounds remain unclear. The present study aims to examine the antibacterial compounds of the moso bamboo shoot skin.

2. Materials and methods

\subsection{Plant material}

Shoot skins of moso bamboo ( $P$. pubescens) were used in this study. They were harvested in the town of Miyako, Fukuoka prefecture, Japan, and were provided by Life Design Co., Ltd. (Fukuoka, Japan). The skins were dried at room temperature and used for the following experiments.

\subsection{Chemicals and reagents}

Nutrient agar (NA) and nutrient broth (NB) media were purchased from Becton, Dickinson and Company (Franklin Lakes, NJ, USA). Dimethylsulfoxide (DMSO), sorbic acid, stigmasterol, and $\beta$-sitosterol were obtained from Wako Pure Chemical Industries, Ltd. (Osaka, Japan).

\subsection{Microorganism strains.}

Staphylococcus aureus (NBRC 12732) and Escherichia coli (NBRC 3301) were purchased from the NITE Biological Resource Center (NBRC, Chiba, Japan).

\subsection{Extraction and isolation}

Moso bamboo shoot skins (powder, $17.8 \mathrm{~kg}$ ) were extracted with of $n$-hexane for 48 hours. The $n$-hexane solution was evaporated, yielding $40.1 \mathrm{~g}$ dry weight of the extract. This extract was treated in $70.5 \mathrm{~L}$ of methanol for 48 hours. After the methanol solution had evaporated, the extract (192.5 g) was soaked in dichloromethane and separated into dichloromethane-soluble (38.8 g) -insoluble (151.5 g) crude extracts.

The dichloromethane-soluble crude extract showed antibacterial activity against $S$. aureus. The soluble extract (35. 5 g) was separated into 16 fractions (Fr. 1-16) by silica-gel column chromatography (1.89 kg of Wakogel: C-200, column $11 \times 45 \mathrm{~cm}$ ) with $n$-hexane/ethyl acetate (10:0, 9:1, 8:2, 7:3, 6:4, 5:5, 4:6, 3:7, 2:8, 1:9, 0:10, 2 or $4 \mathrm{~L}$ each) and methanol (10 L). In these 16 fractions, fr. 4, fr. 5, fr. 14, and fr. 16 showed 
antibacterial activity against S. aureus. Fr. 4 (5.54 g) was further separated into 11 fractions by silica-gel column chromatography (904 g of Wakogel: C-200, column $4.1 \times$ $28.4 \mathrm{~cm}$ ) with $n$-hexane/ethyl acetate $(10: 0,9: 1,8: 2,7: 3,6: 4,5: 5,4: 6,3: 7,2: 8,2 \mathrm{~L}$ each) and methanol (4 L). In these 11 fractions, only fr. 4-4 showed antibacterial activity against both $E$. coli and $S$. aureus. Subsequently, $250 \mathrm{mg}$ of fr. 4-4 was further devided into three fractions (fr. 4-4-1: 67. $5 \mathrm{mg}$, fr. 4-4-2: $62.1 \mathrm{mg}$, fr. 4-4-3: $80.0 \mathrm{mg}$ ) by preparative-high-performance liquid chromatography (HPLC, Inertsil Prep-ODS, 20 mm i.d. × $250 \mathrm{~mm}$; GL Sciences, Tokyo, Japan) at $210 \mathrm{~nm}$. The column was eluted with methanol at a flow rate of $10 \mathrm{~mL} / \mathrm{min}$. Two fractions, fr. 4-4-1 and 4-4-2 showed antibacterial activity against both E. coli and S. aureus. A third, fr. 4-4-3, did not inhibit the growth of bacteria. Fr. 4-4-3 was considered a pure compound by analytical-HPLC (Inertsil ODS-3, $5 \mu \mathrm{m}, 4.5 \mathrm{~mm}$ i.d. $\times 150 \mathrm{~mm}$; GL Sciences, Tokyo, Japan) at $210 \mathrm{~nm}$. The column was eluted with methanol at a flow rate of $1.0 \mathrm{~mL} / \mathrm{min}$. Then, $30 \mathrm{mg}$ of fr. 4-4-2 was further separated into two compounds (fr. 4-4-2-1: $9.1 \mathrm{mg}$ and fr. 4-4-2-2: 7.2 mg) by recycling-HPLC (JAIGEL-GS310, 20 mm i.d. × 500 mm; Japan Analytical Industry Co., Ltd., Tokyo, Japan) at $210 \mathrm{~nm}$. The column was eluted with methanol at a flow rate of $8.0 \mathrm{~mL} / \mathrm{min}$.

Fr. 4-4-2-1, 4-4-2-2 and fr. 4-4-3 were identified as stigmasterol, dihydrobrassicasterol and $\beta$-sitosterol by nuclear magnetic resonance (NMR) and electron impact-mass spectrometry (EI-MS).

Compound 1: Fr. 4-4-2-1, Stigmasterol. The ${ }^{1} \mathrm{H}$ and ${ }^{13} \mathrm{C}$ NMR, EI-MS, optical rotation value and melting point of fr. 4-4-2-1 were identical to those of standard stigmasterol. White powder; ${ }^{1} \mathrm{H}-\mathrm{NMR}\left(\mathrm{CDCl}_{3}, 400 \mathrm{MHz}\right) \delta: 5.35(1 \mathrm{H}, \mathrm{m}, \mathrm{H}-6), 5.15(1 \mathrm{H}, \mathrm{dd}, J=$ 14.7, 8.6 Hz, H-22), 5.01 (1H, dd, $J=15.2,8.8 \mathrm{~Hz}, \mathrm{H}-23), 3.53$ (1H, m, H-3), 1.02 (3H, d, $J=7.44 \mathrm{~Hz}, \mathrm{Me}-21), 0.84$ (3H, t, $J=6.25 \mathrm{~Hz}, \mathrm{Me}-29), 0.80$ (3H, d, J = $7.01 \mathrm{~Hz}$, Me-27), 0.70 (3H, s, Me-18); ${ }^{13} \mathrm{C}-\mathrm{NMR}\left(\mathrm{CDCl}_{3}, 100 \mathrm{MHz}\right) \delta: 140.7,128.4,129.4,71.8$, 56.8, 55.9, 51.2, 50.1, 42.3, 42.2, 40.5, 39.6, 37.2, 36.5, 31.9, 31.6, 28.9, 25.4, 24.4, 21.2, 21.1, 21.0, 19.4, 19.0, 12.3, 12.0; EI-MS (70 eV): $\mathrm{m} / \mathrm{z}=412\left(\mathrm{M}^{+}\right), 395,379,351$, 327, 315, 300, 278, 273, 255; $[\alpha]_{\mathrm{D}}{ }^{23}-32$ (c $=0.8, \mathrm{CHCl}_{3}$ ); mp. $169-170{ }^{\circ} \mathrm{C}$. Also, the optical rotation value and melting point of standard stigmasterol were $[\alpha]_{\mathrm{D}}{ }^{23}-32(\mathrm{c}=0.8$, $\mathrm{CHCl}_{3}$ ) and mp. $169-170{ }^{\circ} \mathrm{C}$, respectively.

Compound 2: Fr. 4-4-2-2, Dihydrobrassicasterol. The ${ }^{1} \mathrm{H}$ and ${ }^{13} \mathrm{C}$ NMR, EI-MS, optical rotation values and melting point of fr. 4-4-2-2 were identical to those reported for synthesized dihydrobrassicasterol by Koizumi et al [15] and Thompson et al [16]. White powder; ${ }^{1} \mathrm{H}-\mathrm{NMR}\left(\mathrm{CDCl}_{3}, 400 \mathrm{MHz}\right) \delta$ : 5.36 (1H, m, H-6), 3.53 (1H, m, H-3), 1.01 (3H, s, H-19), 0.91 (3H, d, $J=5.03$ Hz, H-21), 0.85 (3H, d, $J=6.8$ Hz, H-26), 0.81 (3H, d, J 
= 6.5 Hz H-27), 0.77 (3H, d, J = 6.5 Hz, H-24), 0.68 (3H, s, H-18); ${ }^{13} \mathrm{C}-\mathrm{NMR}\left(\mathrm{CDCl}_{3}\right.$, $100 \mathrm{MHz}) \delta: 140.7,121.7,71.8,56.8,56.1,50.1,42.3,39.7,39.0,37.2,36.5,36.2,33.7$, 31.9, 31.7, 31.4, 30.5, 28.2, 24.3, 21.1, 20.5, 19.4, 18.9, 17.6, 15.4, 11.9; EI-MS (70 $\mathrm{eV}): \mathrm{m} / \mathrm{z}=400\left(\mathrm{M}^{+}\right), 382,367,340,315,289,255,231,213 ;[\alpha]_{\mathrm{D}}^{23}-44(\mathrm{c}=0.1$, $\mathrm{CHCl}_{3}$ ); mp. $158-160{ }^{\circ} \mathrm{C}$. Also, the optical rotation value and melting point of reported dihydrobrasscasterol were $[\alpha]_{\mathrm{D}}{ }^{23}-44\left(\mathrm{c}=0.8, \mathrm{CHCl}_{3}\right)$ and mp. $158-159{ }^{\circ} \mathrm{C}$, respectively.

Compound 3: Fr. 4-4-3, $\beta$-sitosterol. The ${ }^{1} \mathrm{H}$ and ${ }^{13} \mathrm{C}$ NMR, EI-MS, optical rotation value and melting point of fr. 4-4-3 were identical to those of standard $\beta$-sitosterol. White powder; ${ }^{1} \mathrm{H}-\mathrm{NMR}\left(\mathrm{CDCl}_{3}, 400 \mathrm{MHz}\right) \delta: 5.35$ (1H, m, H-6), $3.53(1 \mathrm{H}, \mathrm{m}, \mathrm{H}-3)$, 1.01 (3H, s, H-19), 0.92 (3H, d, $J=6.5$ Hz, H-21), 0.85 (3H, t, $J=7.4$ Hz, H-24), 0.81 (3H, d, $J=6.8 \mathrm{~Hz}, \mathrm{H}-27), 0.68$ (3H, s, H-18); ${ }^{13} \mathrm{C}-\mathrm{NMR}\left(\mathrm{CDCl}_{3}, 100 \mathrm{MHz}\right) \delta: 140.7$. 121.7, 71.9, 56.7, 56.0, 50.1, 45.8, 42.3, 39.8, 37.2, 36.5, 36.1, 33.9, 31.9, 31.6, 29.1, 28.3, 26.0, 24.3, 23.0, 21.1, 19.8, 19.4, 19.0, 18.8, 12.0, 11.9; EI-MS (70 eV): m/z = 414 $\left(\mathrm{M}^{+}\right), 400,396,382,367,329,315,303,289,273,255,231,213 ;[\alpha]_{\mathrm{D}}^{23}-33(\mathrm{c}=0.1$, $\left.\mathrm{CHCl}_{3}\right)$; mp.139-140 ${ }^{\circ} \mathrm{C}$. Also, the optical rotation value and melting point of standard $\beta$-sitosterol were $[\alpha]_{\mathrm{D}}{ }^{23}-33\left(\mathrm{c}=0.8, \mathrm{CHCl}_{3}\right)$ and mp. $140-141^{\circ} \mathrm{C}$, respectively.

\subsection{Determination of antibacterial activity}

A single colony of the test strain was taken and added to $20 \mathrm{~mL}$ of NB medium. This medium was incubated at $37^{\circ} \mathrm{C} \pm 1^{\circ} \mathrm{C}, 160 \mathrm{rpm}$ for 12 hours. It was then added to bacterial suspension to prepare a bacterial concentration at $10^{5} \mathrm{CFU} / \mathrm{mL}$. The bacterial solution was used for the following antibacterial assay. Each sample was dissolved in DMSO at maximum concentration. Into each well of a 96-well plate were added $89 \mu \mathrm{L}$ of NB medium, $10 \mu \mathrm{L}$ of bacteria suspension, and $1 \mu \mathrm{L}$ of DMSO with or without each sample. Also, sorbic acid, which is well used as a food preservative, was used as a positive control. The plate was incubated at $37^{\circ} \mathrm{C} \pm 1^{\circ} \mathrm{C}, 1160 \mathrm{rpm}$ for 12 hours. Finally, bacterial growth was measured by a micro-plate reader $(630 \mathrm{~nm})$. The statistical difference between the control and each sample was determined by Student's t-test.

\section{Results and Discussion}

The antibacterial activities of each extract against $S$. aureus are shown in Figure 1 . The turbidity of 1\%DMSO (control) was 0.184 and that of the dichloromethane-soluble extract was 0.021 . The dichloromethane-soluble extract strongly inhibited the growth of $S$. aureus. On the other hand, the $n$-hexane extract stimulated the growth of $S$. aureus. 
The methanol extract and the dichloromethane-insoluble extract had no effect on the growth of $S$. aureus. The same experiment was applied to E. coli. However, significant antibacterial activity against $E$. coli was not detected from any of the extracts.

As a result of the activity guided-fractionation, compounds 1-3 were isolated from the dichloromethane-soluble extract. The structures of compounds 1-3 were determined by EI-MS and NMR studies. Compounds 1-3 were identified as stigmasterol, dihydrobrassicasterol, and $\beta$-sitosterol, respectively. The structure of each is shown in Figure 2.

The antibacterial activities of compounds 1-3 are shown in Figure 3. Stigmasterol (1) and dihydrobrassicasterol (2) inhibited the growth of $S$. aureus at $200 \mu \mathrm{g} / \mathrm{mL}$. They also showed similar antibacterial activities against E. coli. However, $\beta$-sitosterol did not show any antibacterial activity, and slightly stimulated the growth of E. coli at 200 $\mu \mathrm{g} / \mathrm{mL}$. Stigmasterol and dihydrobrassicaserol showed antibacterial activities against both S. aureus and E. coli. However, dichloromethane soluble extract showed no activity against $E$. coli. There is a possibility that relative concentrations of antibacterial comounds against $E$. coli in dichloromethane soluble extract was not enough for revealing the activity.

Compounds 1-3 have the same steroid skeletons but different side chains. Stigmasterol (1) has the double bond between C22 and C23, and an ethyl group attaches to C24. Dihydrobrassicasterol (2) has no double bond between C22 and C23, and a methyl group attaches to C24. Also, $\beta$-sitosterol (3) has no double bond between C22 and C23, and an ethyl group attaches to C24. It has been reported that some steroidal compounds express thier biological activities in vivo, caused by the reaction between their double bonds in the side chain and protein or peptide [17]. Considering its possibility, stigmasterol (1) may express its antibacterial activity by the similar way. On the other hand, we can not explain the antibacterial activity of dihydrobrassicasterol (2) by this concept, because of its missing of double bond at the side chain. Also, the lengh of alkyl chain of alcohols has been reported to be important to express antibacterial activity [18]. Compared dihydrobrassicasterol (2) with $\beta$-sitosterol (3), the lengh of side chains are different. Dihydrobrassicasterol has a methyl group and $\beta$-sitosterol has a ethyl group at C24. Difference of the length of side chain among them may affect their antibacterial activities. However, further structure-activity relationships and some biochemical studies are needed for understanding their mechanism.

Stigmasterol (1) and $\beta$-sitosterol (3) were identified as the predominant sterols in bamboo shoot [19, 20]. Stigmasterol (1) has been already reported as an antibacterial compound against E. coli and S. aureus [21]. Dihydrobrassicasterol (2) and $\beta$-sitosterol 
(3) are known as bioactive lipids from plant extract [22], and Heinemann and colleagues showed that low doses of free $\beta$-sitosterol (3) were effective in lowering LDL-C levels [23]. Also, this is the first report on the antibacterial activity of dihydrobrassicasterol (2). It should be noted that the bioactivity-guided fractionation led to obtain some antibacterial fractions other than the fraction with stigmasterol (1) and dihydrobrassicasterol (2). However, these compounds $(\mathbf{1}, \mathbf{2})$ were isolated from dominant antibacterial fraction. Therefore they may primarily contribute antibacterial activity of bamboo shoot skins.

Thus far, bamboo shoot skins have been used mainly for composting. However, this study elucidated some antibacterial compounds contained in bamboo shoot skins and established the possibility that bamboo shoot skins could serve as antibacterial materials. The result of this study may make it possible to utilize bamboo shoot skins more effectively. 


\section{Acknowledgement}

Hyo Jung Kim contributed to extraction and fractionation in the experiments performed in this study. We are thankful to Dr. Miyamoto for optical rotation measurement. The costs of publication were supported in part by the Research Grant for Young Investigators of Faculty of Agriculture, Kyushu University. 


\section{References}

1. Ishiwatari S, Suzuki T, Hitomi T, Yoshino T, Matsukuma S, Tsuji T (2007) Effects of methyl paraben on skin keratinocytes. Journal of Applied Toxicology 27:1-9.

2. Handa O, Kokura S, Adachi S, Takagi T, Naito Y, Tanigawa T, Yoshida N, Yoshikawa $\mathrm{T}$ (2006) Methylparaben potentiates UV-induced damage of skin keratinocytes. Toxicology 227:62-72.

3. Jacquelyn G. Black (2007), Microbiology, Maruzen Co. Ltd., Tokyo, pp.686 - 687.

4. Lee H.-O, Baek S.-H, Han D.-M (2001) Antimicrobial effects of Chamaecyparis obtusa essential oil. Korean Journal of Applied Microbiology and Biotechnology 29:253-257.

5. Zhang Y, Jiao J, Liu C, Wu X, Zhang Y (2008) Isolation and purification of four flavone C-glycosides from antioxidant of bamboo leaves by macroporous resin column chromatography and preparative high-performance liquid chromatography. Food Chemistry 107:1326-1336.

6. Lu B.-Y, Zhang Y, Wu X.-Q (2005) Advances in studies on antioxidative activity and cardio-cerebrovascular pharmacology of bamboo-leaf-flavonoids. Linchan Нuaxue Yu Gongye/Chemistry and Industry of Forest Products 25:120-124.

7. Jiao J, Zhang Y, Liu C, Liu J, Wu X, Zhang Y (2007) Separation and purification of tricin from an antioxidant product derived from bamboo leaves. Journal of Agricultural and Food Chemistry 55:10086-10092.

8. Hasegawa T, Tanaka A, Hosoda A, Takano F, Ohta T (2008) Antioxidant C-glycosyl flavones from the leaves of Sasa kurilensis var. gigantean. Phytochemistry 69: 1419-1424.

9. Zhang Y, Yao X, Bao B, Zhang Y (2006) Anti-fatigue activity of a triterpenoid-rich extract from chinese bamboo shavings (Caulis bamfusae in taeniam). Phytotherapy Research 20:872-876.

10. Kurokawa T, Itagaki S, Yamaji T, Nakata C, Noda T, Hirano T, Iseki K (2006) Antioxidant activity of a novel extract from bamboo grass (AHSS) against ischemia-reperfusion injury in rat small intestine. Biological and Pharmaceutical Bulletin 29:2301-2303.

11. Nishina A, Hasegawa K.-I, Uchibori T, Seino H, Osawa T (1991) 2,6-dimethoxy-p-benzoquinone as an antibacterial substance in the bark of Phyllostachys heterocycla var. Pubescens, a species of thick-stemmed bamboo. Journal of Agricultural and Food Chemistry 39:266-269.

12. Fujimura M, Ideguchi M, Minami Y, Watanabe K, Tadera K (2005) Amino acid sequence and antimicrobial activity of chitin-binding peptides, Pp-AMP 1 and 
Pp-AMP 2, from Japanese bamboo shoots (Phyllostachys pubescens). Bioscience, Biotechnology and Biochemistry 69:642-645.

13. Katsuzaki H, Sakai K, Achiwa Y, Imai K, Komiya T (1999) Isolation of antioxidative compounds from bamboo shoots sheath. Nippon Shokuhin Kagaku Kogaku Kaishi 46:491-493.

14. Tanaka A, Kim H.J, Oda S, Shimizu K, Kondo R (2011) Antibacterial activity of moso bamboo shoot skin (Phyllostachys pubescens) against Staphylococcus aureus. Journal of wood science 57(6):542-544.

15. Koizumi N, Fujimoto Y, Takeshita T, Ikekawa N (1979) Carbon-13 nuclear magnetic resonance of 24-substituted steroids. Chem. Pharm. Bull. 27:38-42.

16. Thompson Malcom J, Cohen Charles F, Lancaster Stanton M (1965) Brassicasterol and 22, 23-dihydrobrassicasterol from ergosterol via i-ergosterol. Steroids 5(6): 745-752.

17. Tachibana Y (2006) Synthesis and Structure-Activity Relationships of Bioactive Compounds Using Steroids. Yakugaku Zasshi. 126(11): 1139-1154

18. Kubo I, Muroi H, Kubo A (1995) Structural functions of antimicrobial long-chain alcohols and phenols. Bioorganic and Medicinal Chemistry. 3(7): 873-880.

19. He YH, Lachance PA. (1998) Effects of dietary bamboo shoot on fecal neutral sterols and bile acid excretion in the rat. FASEB J 12(4):210.

20. Lachance PA, He YH. (1998) Hypocholesterolemic compositions from bamboo shoots. PCT Intl. Patent, PCT/US98/12556.

21. Jain S.C, Singh B, Jain R. (2001) Antimicrobial activity of triterpenoids from Heliotropium ellipticum. Fitoterapia 72 (6):666-668.

22. Nagao K, Yanagita T. (2008) Bioactive lipids in metabolic syndrome. Progress in Lipid Research 47 (2):127-146.

23. Heinemann T, Leiss O, von Bergmann K. (1986) Effect of low-dose sitostanol on serum cholesterol in patients with hypercholesterolemia. Atherosclerosis 61:219-223. 


\section{Figure legends}

Figure 1. Antibacterial activities of each extract from bamboo shoot skin against $S$. aureus. The values were represented as the mean \pm standard deviation (SD) of experiments performed in triplicate. Final concentration $(\mu \mathrm{g} / \mathrm{mL})$ of each extract was showed in case arc. Significant difference between $1 \% \mathrm{DMSO}$ and each extract was determined by Student's t-test: ${ }^{*} P<0.05$, ${ }^{* *} P<0.01$.

Figure 2. Structures of stigmasterol (1), dihydrobrassicasterol (2) and $\beta$-sitosterol (3).

Figure 3. Antibacterial activities of compounds 1-3 against S. aureus and E. coli. The values were represented as the mean \pm standard deviation (SD) of experiments performed in triplicate. Significant difference between 1\%DMSO and each extract was determined by Student's t-test: ${ }^{*} P<0.05$, ${ }^{* *} P<0.01$. Each compound was dissolved in DMSO and the final concentration was $200 \mu \mathrm{g} / \mathrm{mL}$. 


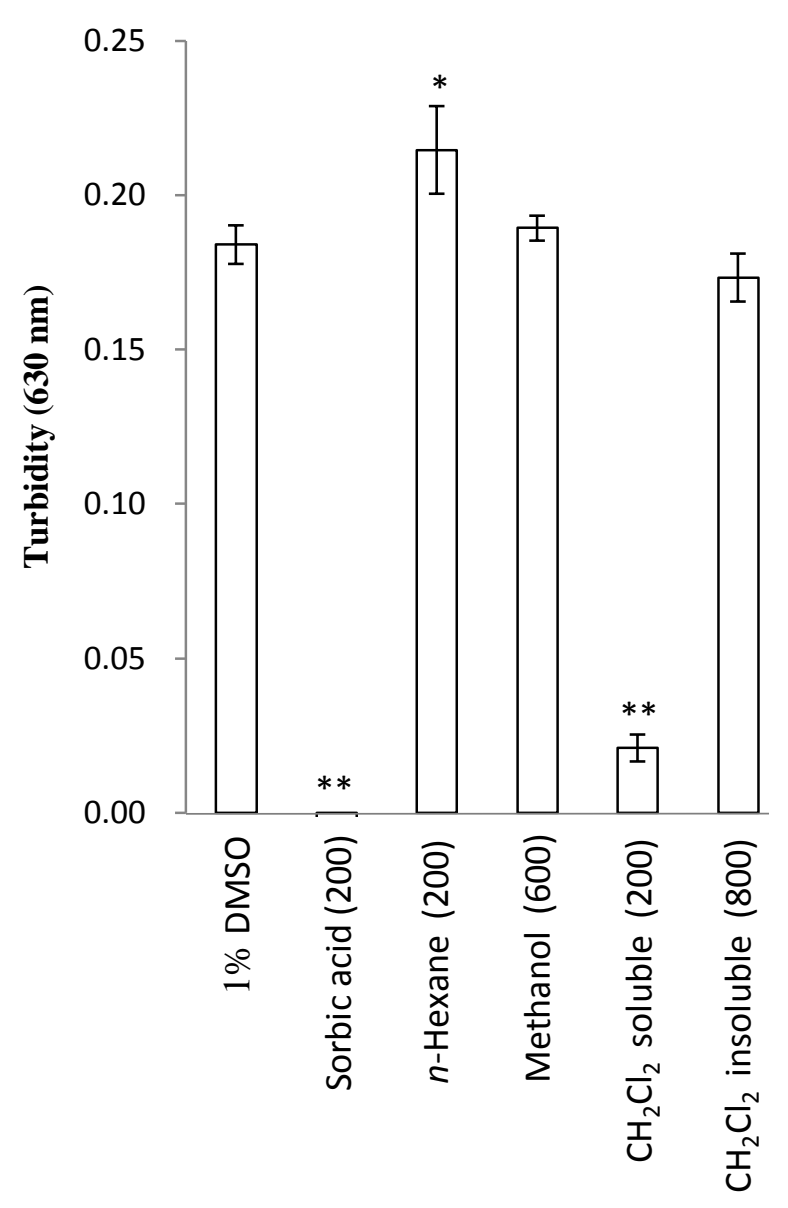

Figure 1. Antibacterial activity of crude extracts from bamboo shoot skin against $S$. aureus. 

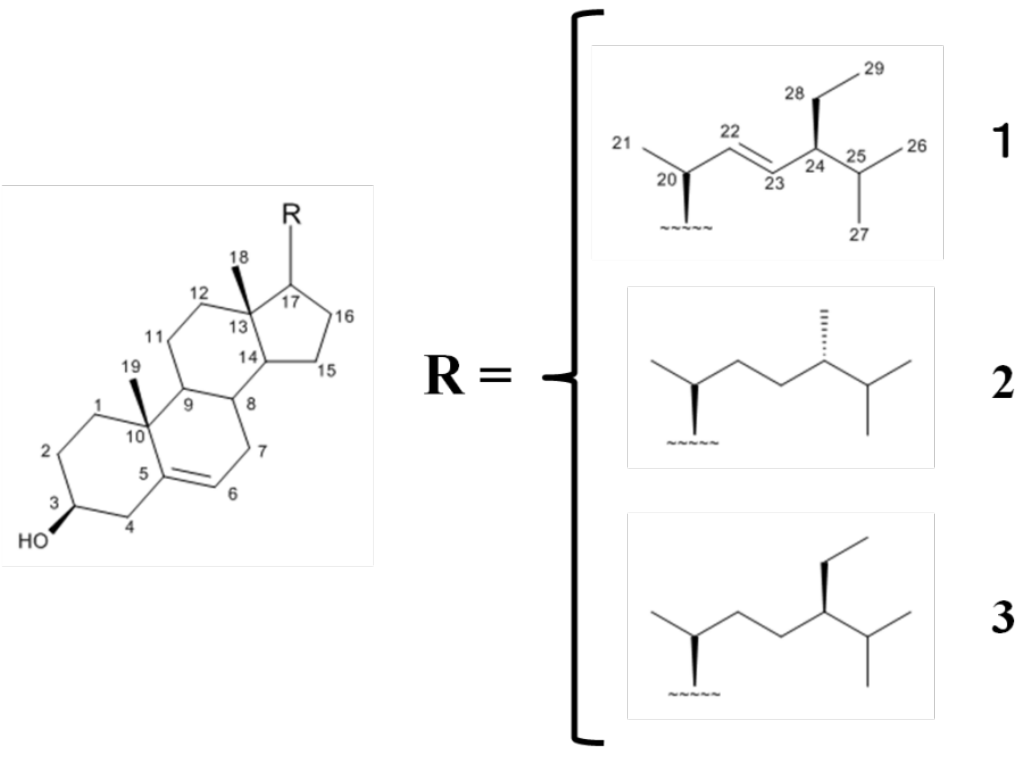

Figure 2. Structures of stigmasterol (1), dihydrobrassicasterol (2) and $\beta$-sitosterol (3). 


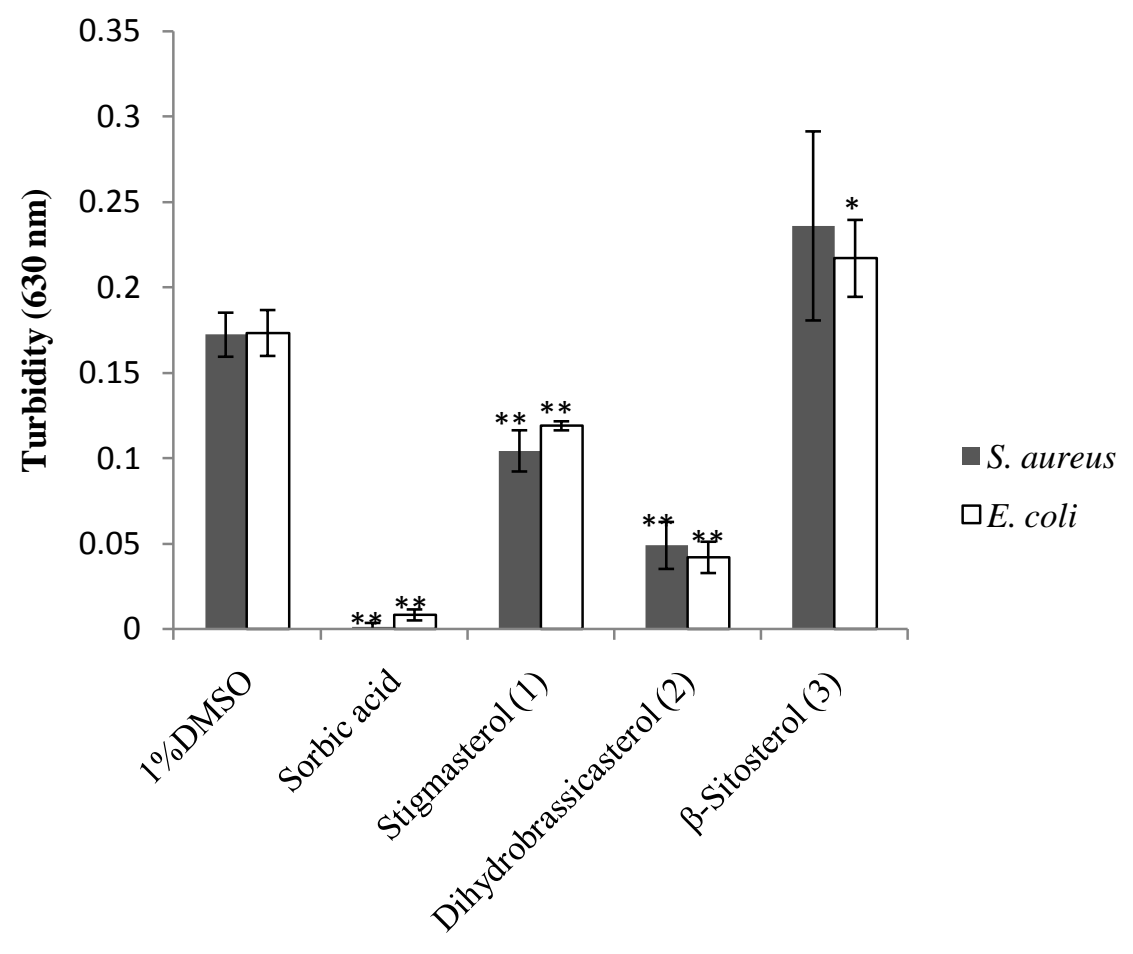

Figure 3. Antibacterial activity of Compounds 1-3 against $S$. aureus and $E$. coli. 